\title{
Nucleation, Agglomeration and Crystal Morphology of Calcium Carbonate
}

\author{
Clifford Y. Tai and Pao-Chi Chen \\ Dept. of Chemical Engineering, National Taiwan University, Taipei, Taiwan 106, R.O.C.
}

\begin{abstract}
A pH-stat MSMPR crystallizer is used to obtain the nucleation rate equation of calcite formed in the $\mathrm{Na}_{2} \mathrm{CO}_{3}-\mathrm{CaCl}_{2}$ reacting system. The experiments are conducted for seeded and unseeded runs. Effects of breakage and agglomeration on the crystalsize distribution are demonstrated. In a continuous operation, the agglomeration of nuclei followed by the breakage of agglomerates occurs at the transient state, while the agglomeration is significant at the steady state. Taking crystal agglomeration into account, the corrected nucleation rate and agglomeration rate are obtained simultaneously. The agglomeration rate is a function of relative supersaturation and magma density, and the corrected nucleation rate is approximately two- to fivefold of the apparent nucleation rate, which is the nucleation rate without considering the agglomeration effect. Discussed also is the formation of calcium carbonate polymorphism.
\end{abstract}

\section{Introduction}

Calcium carbonate is the most widely studied system among sparingly soluble substances because of its importance in the fields of sedimentology, oceanology, wastewater treatment, paint and paper fillers, and desalination. Calcium carbonate nucleates in three forms from aqueous solution, that is, calcite, aragonite and vaterite, depending on the operational conditions. Usually, high supersaturation favors the formation of vaterite (Söhnel and Mullin, 1982; Hostomsky and Jones, 1991; Bhatia and Chakraborty, 1992) and dendritic aragonite (Peters and Chang, 1987; Tai et al., 1993), which is easily agglomerated to form a rosette particle morphology. On the other hand, calcite nucleates at mild supersaturation (Peters and Chang, 1987; Tai et al., 1993) and moderate temperature as rhombohedron (Wray and Daniels, 1957). However, the crystal forms of sparingly soluble salts produced by the primary mechanism are difficult to control. Operating conditions, such as solution composition, $\mathrm{pH}$, temperature, additives and agitation speed, are important factors as far as the crystal habit, particle morphology (Söhnel and Mullin, 1982; Swinney et al., 1982; Peters and Chang, 1987; Hostomsky and Jones, 1991; Garside, 1992; Chen et al., 1992) and polymorphism are concerned (Wray and Daniels, 1957).

Crystallization of calcium carbonate was studied extensively with emphasis on the growth mechanism of calcite by a $\mathrm{pH}$ stat method (Kazmlerczak et al., 1992; Giannimaras and
Koutsoukos, 1987; Christoffersen and Christoffersen, 1990) and on the primary nucleation from an MSMPR crystallizer (Schierhoiz and Stevens, 1975; Swinney et al., 1982; Tsuge et al., 1987; Hostomsky and Jones, 1991). These authors did not investigate the contact breeding and agglomeration of calcite crystals. On the other hand, the contact breeding of sparingly soluble salts have been found by Etherton and Randolph (1981) for gypsum and by Tai et al. (1993) for calcite. Generally speaking, the secondary nucleation rate was correlated with growth rate and magma density to provide the kinetics expression:

$$
B^{0}=K_{b} G^{1} M_{t}^{j}
$$

In general, agglomeration is unavoidable in the crystallization or precipitation of sparingly soluble salts. The determination of nucleation rate in the presence of agglomeration is difficult, because the number of particles is reduced to a great extent. Several methods are available for determining the degree of agglomeration in the crystallization systems. The first one was suggested by Liao and Hulburt (1976) who proposed a model to determine the nucleation rate, growth rate and agglomeration rate simultaneously from the steadystate CSD. The method was also employed by Tavare et al. 
(1985) to obtain agglomeration rate of nickle ammonium sulfate. Recently, Tavare and Patwardhan (1992) utilized this method and combined it with the method of moment (Hulburt and Katz, 1964) to express the nucleation rate of copper sulfate pentahydrate crystals as Eq. 1, and the agglomeration kinetics as:

$$
\beta=K_{\beta} G^{h}\left(B^{0}\right)^{p} \tau^{q}
$$

Other techniques to study the agglomeration kinetics have been reported in the literature, for example, the method of classes (Marchal et al., 1988; Hounslow, 1990; Hostomsky and Jones, 1991), Smoluchowaki's theory (Ring, 1990; Dirksen et al., 1990), modified MWR method (Bhatia and Chakraborty, 1992), and visual technique (Budz et al., 1987).

In this work, large calcite crystals $(325 \mu \mathrm{m})$, which were prepared by gel growth technique, were suspended in the $\mathrm{Na}_{2} \mathrm{CO}_{3}-\mathrm{CaCl}_{2}$ reacting system to study the contact nucleation, using a pH-stat mixed suspension, mixed product removal (MSMPR) crystallizer. In order to compare the nucleation rates with and without the effect of agglomeration, a new model was proposed to determine the corrected nucleation rate and agglomeration rate simultaneously. Additionally, the polymorphism of calcium carbonate was also discussed, using the experimental data obtained in this work and elsewhere reported in the literature.

\section{Determination of Nucleation Rate and Agglomer- ation Rate}

Randolph and Larson (1988) introduced the macroscopic population balance equation as:

$$
\frac{\partial n}{\partial t}+\frac{\partial(G n)}{\partial L}+r_{b}+r_{a}+\frac{n}{V} \frac{\partial V}{\partial t}=-\sum_{k} \frac{n_{k} Q_{k}}{V}
$$

where $r_{a}$ is the agglomeration rate, and $r_{b}$ is the breakage rate. Suppose that there is no breakage $\left(r_{b}=0\right)$, the population balance equation at steady state may be simplified to:

$$
\frac{d(n G)}{d L}+\frac{n}{\tau}=-r_{a}
$$

Since $n(\infty)$ is zero at $L=\infty$, Eq. 4 can be multiplied by $d L$, and then integrated to give:

$$
n(L) G(L)-N(L) / \tau=R_{a}
$$

where $N(L)$ and $R_{a}$ are defined as:

$$
N(L)=\int_{L}^{\infty} n(L) d L
$$

and

$$
R_{a}=\int_{L}^{\infty} r_{a} d L
$$

The agglomeration rate, $r_{a}$, is defined by Sastry and Fuerstenau (1970):

$$
-r_{a}=\frac{d n_{k}}{d t}=-A n_{k} N+\frac{1}{2} \sum_{l=1}^{k-1} A n_{l} n_{k-1}
$$

Where $n_{k}, n_{l}$ and $n_{k-1}$ are average numbers of particles per unit volume at particle size $K, 1$ and $K-1$ respectively, and $A$ is the agglomeration rate constant. Equation 8, after summarizing the number of particles, can be written:

$$
\frac{d N}{d t}=\frac{d}{d t} \sum_{k=1}^{\infty} n_{k}=\sum_{k=1}^{\infty}\left(\frac{1}{2} \sum_{l=1}^{k-1} A n_{i} n_{k-1}-A n_{k} N\right)=-\frac{1}{2} A N^{2}
$$

where $N$ is the total number of particles:

$$
N=\sum_{k=1}^{\infty} n_{k}
$$

and the agglomeration rate, $R_{a}$, is:

$$
R_{a}=-\int_{L}^{\infty} \frac{d n_{k}}{d t} d L=-\frac{d}{d t}\left(\sum_{k=1}^{\infty} n_{k}\right)=-\frac{d N}{d t}
$$

Substituting Eq. 9 into Eq. 11, the agglomeration rate, $R_{a}$, becomes:

$$
R_{a}=\frac{A}{2} N^{2}
$$

If Eq. 12 is substituted into Eq. 5, the following equation is obtained:

$$
\frac{N}{\tau}=n(L) G(L)-\frac{A}{2} N^{2}
$$

Next, we assume a power-law model for nucleation kinetics and agglomeration kinetics (Mullin, 1972; Halfon and Kaliaguine, 1976; Budz et al., 1987; Zumstein and Rousseau, 1989):

$$
B=n G=K_{b} M_{i}^{i} \sigma^{j}
$$

and

$$
A=K_{a} M_{7}^{m} \sigma^{t}
$$

Substituting Eq. 14 and Eq. 15 into Eq. 13, we obtain the following equation:

$$
\frac{N}{\tau}=K_{b} M_{f}^{i} \sigma^{j}-K_{a}\left(\frac{N^{2}}{2}\right) M_{t}^{m} \sigma^{\prime}
$$

where $K_{a}, K_{b}, i, j, m$ and $l$ are kinetic parameters, which can be evaluated using nonlinear regression analysis with given values of $N, \tau, \sigma$ and $M_{t}$ (magma density). In order to evaluate the total number $N(L)$, the population density is expressed as an empirical form (Jones et al., 1986):

$$
\operatorname{Ln} n(L)=P_{1} \exp \left(P_{2} L+P_{3} L^{0.5}\right)
$$


Parameters, $P_{1}, P_{2}$ and $P_{3}$, are determined by the linear regression analysis. Assuming no agglomeration, Eq. 13 is reduced to:

$$
\frac{N}{\tau}=n G=B=K_{b} M_{t}{ }^{i} \sigma^{j}
$$

which is identical to $\mathrm{Eq} .14$.

\section{Experimental Procedures \\ Preparation of seed crystals}

The seed crystals were prepared by the gel growth technique (Henisch, 1973). The experimental procedure was similar to that reported in the previous study (Tai et al., 1993). The SEM photograph and $x$-ray powder diffraction data show that the seed crystals are calcite of rhombohedron.

\section{Crystallization system}

An MSMPR crystallization system for the secondary nucleation study of calcite was illustrated in Figure 1. The crystallization system consists of a pH controller, a 2.71 acrylic plastic crystallizer fitted with an axial-flow steel-made agitator, a heating element, and a liquid level controller. The diameter and height of the crystallizer are $140 \mathrm{~mm}$ and $180 \mathrm{~mm}$, respectively. The crystallizer is baffled with four longitudinal

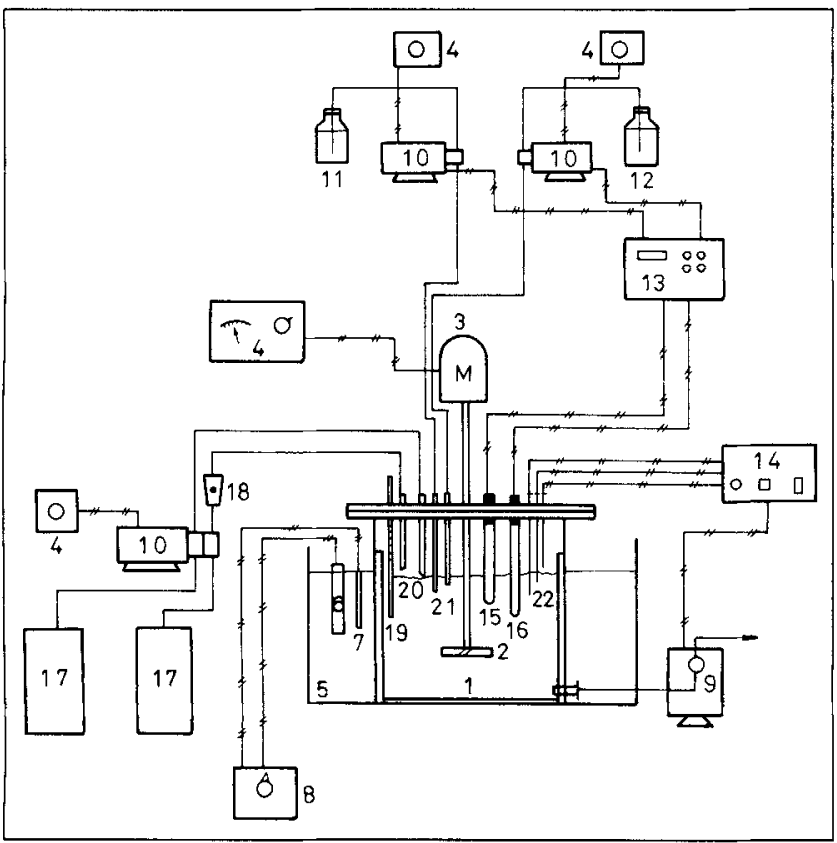

Figure 1. pH.Stat MSMPR crystallization system.
1. Crystallizer
2. Axial flow agitator
3. Motor
4. Speed controllers
5. Water bath
6. Heater
7. Temperature sensor
8. Temperature controller
9. Discharge pump
10. Tubing pump
11. Acid bottle

baffles, each of which is $12 \mathrm{~mm}$ in width and at $90^{\circ}$ spacing. The diameter of agitator is $50 \mathrm{~mm}$. The experiments were conducted at $30^{\circ} \mathrm{C}$ and $800 \mathrm{rpm}$.

Prior to operation, the $\mathrm{pH}$ electrode was standardized with buffers of $\mathrm{pH} 7.0$ and 9.0 , respectively. A supersaturated solution of two liters was prepared by adding sodium carbonate solution into the calcium chloride solution already in the crystallizer. Subsequently, the solution was adjusted to the desired $\mathrm{pH}$ value by adding $0.1 \mathrm{M}$ hydrochloric acid. After the $\mathrm{pH}$ value became steady, a weighted amount of calcite seeds was introduced into the crystallizer. Simultaneously, two equal molar streams of sodium carbonate and calcium chloride solutions were charged into the crystallizer by a tubing pump. The $\mathrm{pH}$ was maintained constant during operation by adding acid $(\mathrm{HCl})$ or base $(\mathrm{NaOH})$ into the crystallizer through the action of a $\mathrm{pH}$ controller. The $\mathrm{pH}$ values of the solution were performed in the range from 8.50 to 9.50 . At the same time, the liquid level was controlled to $\pm 1 / 15$ of the initial liquid level by a discharge pump of diaphragm type. A sieve screen was fixed at the outlet of the crystallizer to prevent the seed crystals flowing out of the crystallizer. To determine the total calcium ion concentration and number density of nuclei generated from contact breeding, the solution slurry excluding the seed crystals was withdrawn by a syringe every $50 \mathrm{~min}$. A part of the solution slurry was poured immediately into a transparent cell and the number density of nuclei was measured by the computerized inspection system (Galai CIS-1). Morphology of product crystals were determined by the FTIR spectra and the scanning electron microscopy (SEM) photographs respectively. On the other hand, a part of the solution slurry of calcium carbonate was filtered with a $0.22 \mu \mathrm{m}$ filter to remove solids from solution. Subsequently, the EDTA potentiometric titration method was applied to determine the total calcium ion concentration of the clear solution.

Another crystallization system, a pH-stat semibatch crystallizer, has been used in our laboratory to study the crystallization of calcium carbonate (Tai et al., 1993). The operating conditions of both experiments are shown in Table 1. In the $\mathrm{pH}$-stat semibatch crystallizer the solution $\mathrm{pH}$ was kept constant by a $\mathrm{pH}$-stat apparatus, controlling the amount of sodium carbonate solution added to the crystallizer. While the solution $\mathrm{pH}$ in the continuous MSMPR crystallizer was held to a certain level by a $\mathrm{pH}$ controller, adjusting the volume of acid or base pumped to the crystallizer.

\section{Steady-state operation}

A steady-state operation is demonstrated with the measured TCA and number density. Figure 2 shows the change of number density and total calcium concentration with operating time for run S-14. The TCA decreased with time before $600 \mathrm{~min}$, but became constant after three residence times. The number density increased rapidly and became slightly oscillated when the operating time was greater than $600 \mathrm{~min}$. This was probably due to CSD instability existing in an MSMPR crystallizer (Randolph and Larson, 1988).

\section{Determination of relative supersaturation}

The relative supersaturation of sparingly soluble salts (Nielsen and Toft, 1984) is given by: 
Table 1. Crystallization Conditions of Calcium Carbonate in MSMPR and Semibatch Crystallizers

\begin{tabular}{|c|c|}
\hline MSMPR Crystallizer & \\
\hline $\begin{array}{l}\text { Feed Conc., } \mathrm{kmol} / \mathrm{m}^{3} \\
\mathrm{Na}_{2} \mathrm{CO}_{3} \\
\mathrm{CaCl}_{2}\end{array}$ & $\begin{array}{l}5.44 \times 10^{-3}-9.43 \times 10^{-3} \\
5.44 \times 10^{-3}-6.88 \times 10^{-3}\end{array}$ \\
\hline $\begin{array}{l}\text { Feed Rates of } \mathrm{Na}_{2} \mathrm{CO}_{3} \text { and } \\
\qquad \mathrm{CaCl}_{2} \text { Streams, } \mathrm{m}^{3} / \mathrm{s}\end{array}$ & $1.0 \times 10^{-7}-1.0 \times 10^{-6}$ \\
\hline $\begin{array}{l}\text { Vol. of Solution in } \\
\text { Agitated Tank, } \mathrm{m}^{3}\end{array}$ & $2.00 \times 10^{-3}$ \\
\hline $\mathrm{pH}$ range & $8.50-9.50$ \\
\hline Residence Time, min & $50-330$ \\
\hline Agitation Speed, rpm & 800 \\
\hline Seed Weight, kg & $2.20 \times 10^{-4}-1.20 \times 10^{-3}$ \\
\hline Seed Size, $\mu \mathrm{m}$ & 325 \\
\hline Temperature, ${ }^{\circ} \mathrm{C}$ & 30 \\
\hline $\begin{array}{l}\text { Conc. of Acid/Base } \\
\text { in } \mathrm{pH} \text { Control System, } \mathrm{kmol} / \mathrm{m}^{3}\end{array}$ & 0.1 \\
\hline \multicolumn{2}{|l|}{ pH-Stat Semibatch Crystallizer } \\
\hline $\begin{array}{l}\text { Total Calcium Conc. } \\
\text { at Initial State, } \mathrm{kmol} / \mathrm{m}^{3}\end{array}$ & $1.36 \times 10^{-3}-5.44 \times 10^{-3}$ \\
\hline $\begin{array}{l}\text { Total Carbonate Conc. } \\
\text { at Initial State, } \mathrm{kmol} / \mathrm{m}^{3}\end{array}$ & $2.00 \times 10^{-4}-1.88 \times 10^{-3}$ \\
\hline $\begin{array}{l}\text { Conc. of Titrant, } \mathrm{kmol} / \mathrm{m}^{3} \\
\text { (Sodium Carbonate) }\end{array}$ & $4.72 \times 10^{-3}-9.43 \times 10^{-3}$ \\
\hline $\begin{array}{l}\text { Vol. of Solution in } \\
\text { Agitated Tank at Initial State, } \mathrm{m}^{3}\end{array}$ & $1.00 \times 10^{-3}$ \\
\hline pH Range & $8.50-10.00$ \\
\hline Temperature, ${ }^{\circ} \mathrm{C}$ & 30 \\
\hline Seed Size, $\mu \mathrm{m}$ & $137-230$ \\
\hline Seed Weight, $\mathrm{kg}$ & $2.00 \times 10^{-5}-9.00 \times 10^{-5}$ \\
\hline Agitation Speed, rpm & 800 \\
\hline Operating Time, min & $240-750$ \\
\hline
\end{tabular}

$$
\sigma=\left(I P^{1 / 2}-K_{s p}^{1 / 2}\right) / K_{s p}^{1 / 2}
$$

where $I P$ is the ionic product, $a_{\mathrm{Ca}^{+2}} \cdot a_{\mathrm{CO}_{3}^{-2}}$ and $K_{s p}$ is the solubility product. Activities of species in the supersaturated solution were computed by the successive approximation of ionic

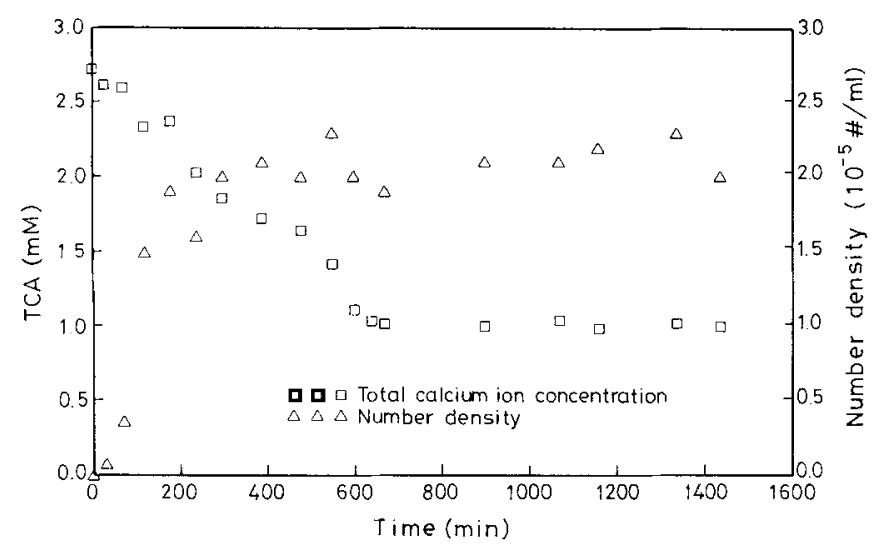

Figure 2. Total calcium ion concentration and number density of run S-14.
Table 2. Operating Variables of Calcium Carbonate Crystallization in a Continuous Crystallizer for Seeded and Unseeded Experiments at $30^{\circ} \mathrm{C}$ and $800 \mathrm{rpm}$

\begin{tabular}{|c|c|c|c|c|c|c|c|}
\hline $\begin{array}{l}\text { Run } \\
\text { No. }\end{array}$ & $\mathrm{pH}$ & $\begin{array}{c}\tau \\
(\mathrm{min})\end{array}$ & $\begin{array}{l}\text { Seed Wt. } \\
\left(10^{6}\right)(\mathrm{kg})\end{array}$ & $\begin{array}{c}M_{t} \\
\left(\mathrm{~kg} / \mathrm{m}^{3}\right)\end{array}$ & $\begin{array}{c}\operatorname{TCA}\left(10^{3}\right) \\
\left(\mathrm{kmol} / \mathrm{m}^{3}\right)\end{array}$ & $\begin{array}{c}\mathrm{TCl}\left(10^{3}\right) \\
\left(\mathrm{kmol} / \mathrm{m}^{3}\right)\end{array}$ & $\sigma^{*}$ \\
\hline S-1 & 8.65 & 143 & 250 & 0.041 & 1.59 & 4.65 & 1.76 \\
\hline S-2 & 8.65 & 100 & 250 & 0.022 & 1.77 & 5.23 & 2.12 \\
\hline$S-3$ & 8.65 & 330 & 250 & 0.057 & 1.45 & 4.21 & 1.49 \\
\hline S-4 & 8.75 & 100 & 254 & 0.054 & 1.59 & 4.75 & 2.30 \\
\hline S-5 & 8.75 & 167 & 260 & 0.035 & 1.70 & 4.76 & 2.08 \\
\hline$S-6$ & 8.80 & 110 & 313 & 0.016 & 1.54 & 4.81 & 2.84 \\
\hline S-7 & 8.90 & 200 & 264 & 0.083 & 1.28 & 3.96 & 2.91 \\
\hline S-8 & 8.75 & 200 & 250 & 0.082 & 1.54 & 4.70 & 2.40 \\
\hline S.9 & 8.50 & 200 & 246 & 0.026 & 1.91 & 6.07 & 2.36 \\
\hline S-10 & 8.50 & 110 & 256 & 0.033 & 1.86 & 5.92 & 2.30 \\
\hline S-11 & 8.50 & 330 & 264 & 0.071 & 1.60 & 4.83 & 1.53 \\
\hline S-12 & 8.75 & 250 & 425 & 0.072 & 1.52 & 4.40 & 2.18 \\
\hline S-13 & 8.75 & 110 & 226 & 0.105 & 1.50 & 4.65 & 2.46 \\
\hline S-14 & 8.75 & 250 & 316 & 0.180 & 1.22 & 3.69 & 1.71 \\
\hline$S-15$ & 8.50 & 200 & 788 & 0.070 & 1.52 & 4.79 & 1.70 \\
\hline S-16 & 8.75 & 330 & 1200 & 0.085 & 1.08 & 3.45 & 1.81 \\
\hline S-17 & 9.00 & 330 & 275 & 0.168 & 0.99 & 3.43 & 3.25 \\
\hline S-18 & 9.25 & 330 & 239 & 0.089 & 1.19 & 3.63 & 4.07 \\
\hline U-19 & 9.00 & 200 & - & 0.137 & 1.48 & 4.58 & 3.63 \\
\hline U-20 & 9.00 & 83 & - & 0.171 & 1.71 & 5.32 & 4.31 \\
\hline U-21 & 9.00 & 117 & - & 0.158 & 1.36 & 4.21 & 3.30 \\
\hline$U-22$ & 9.00 & 350 & - & 0.119 & 1.45 & 4.50 & 3.58 \\
\hline U-23 & 9.00 & 63 & - & 0.226 & 1.46 & 4.52 & 4.04 \\
\hline U-24 & 9.00 & 83 & - & 0.091 & 2.02 & 6.29 & 5.13 \\
\hline $\mathrm{U}-25$ & 9.00 & 60 & - & 0.210 & 1.25 & 3.80 & 2.82 \\
\hline U-26 & 9.00 & 50 & - & 0.239 & 1.08 & 3.58 & 4.71 \\
\hline U-27 & 9.00 & 50 & - & 0.295 & 0.95 & 2.85 & 4.65 \\
\hline U-28 & 9.00 & 83 & - & 0.085 & 1.58 & 3.57 & 3.51 \\
\hline
\end{tabular}

*The relative supersaturation, $\sigma$, was evaluated at the steady-state condition.

strength (Nancollas, 1966) as reported by Tai et al. (1993). In addition, the concentration of nonreacting components, that is, sodium ion and chloride ion, at steady state was evaluated by mass balance:

$$
C_{2}=\frac{Q_{1} C_{1}+Q_{o} C_{o}}{2 Q_{1}+Q_{o}}
$$

where $C_{o}$ is the concentration of acid or base, $C_{1}$ the feed concentration, $Q_{0}$ the volumetric flow rate of acid or base, and $Q_{1}$ the feed rate. The derivation of Eq. 20 has been shown by Chen (1992).

\section{Results and Discussion}

Eighteen runs with seeding and ten runs without seeding were conducted in this experiment. The operating variables of each run are listed in Table 2 . Solution $\mathrm{pH}$, mean residence time, seed weight, and magma density are presented. Since the consumption of TCO is equal to the consumption of TCA, which can be measured, and TNA and TCl can be estimated by Eq. 20 , the relative supersaturation, $\sigma$, were calculated at a given $\mathrm{pH}$ value (Chen, 1992). The calculated values of $\sigma$ are also presented in the table. From the experimental results, the nucleation and agglomeration rates of calcite can be determined. Consequently, the agglomeration mechanism of calcite 
is discussed and the polymorphism of calcium carbonate can be correlated with the supersaturation level.

\section{Nucleation rate and agglomeration rate}

The nucleation rate and agglomeration rate were evaluated from the population density data. Figure 3 shows a typical plot of population density curve. Using population density data, parameters $P_{1}, P_{2}$, and $P_{3}$ in Eq. 17 were obtained by the linear regression analysis. Therefore, total crystal number $N(L)$ can be estimated by numerical integration according to Eq. 6 and Eq. 17. Values of $n(L), B$ and $N(L)$ at crystal size of $3 \mu \mathrm{m}$ were presented in Table 3 . Without considering the effect of agglomeration, the effective nucleation rate equation of calcite at $3 \mu \mathrm{m}$ were obtained from a regression analysis as follows:

$$
B^{*}=9.22 \times 10^{6} \sigma^{0.52} M_{t}^{0.54}
$$

On the other hand, the effective nucleation kinetic parameters and agglomeration parameters were obtained simultaneously by considering the effect of agglomeration. According to Eq. 16 , a corrected nucleation rate equation so obtained is:

$$
B_{\text {cor }}^{*}=5.07 \times 10^{7} \sigma^{1.62} M_{t}^{1.02}
$$

and the agglomeration rate is:

$$
R a=3.73 \times 10^{-15} \sigma^{3.76} M_{t}^{0.52} N^{2}
$$

Values of parameters in Eqs. 21-23 were calculated from the results of 16 runs of seeded experiment for $\sigma$ smaller than 3 in Table 2. For experimental runs with $\sigma$ above 3, the primary nucleation was believed to dominate and the experimental data were excluded in the analysis. The relative root-mean-square errors in natural logarithmic variables of $B^{*}$ in Eq. 3 and $N /$ $\tau$ in Eq. 16 are $4.5 \%$ and $7.7 \%$, respectively.

The ratios of nucleation rate, $B_{\text {cor }}^{*} / B^{*}$, were estimated to be in the range 2 to 5 . This indicated that the nucleation rate of calcite was strongly affected by agglomeration. Evidences of agglomeration are shown in Figure $4 \mathrm{a}-4 \mathrm{~b}$. Ratios of $B_{\text {cor }}^{*} /$ $B^{*}$ in the two runs, run S-2 and run S-8, are 2.07 and 4.32, respectively, indicating that the agglomeration is extensive in run S-8. This result is consistent with the photographic observation. Budz et al. (1987) also found that the nucleation rate corrected for agglomeration are about $30 \%$ higher for the potassium sulfate system. Equation 23 shows that the agglomeration rate increases with increasing supersaturation and magma density. Similar results have been reported in the literature for different systems (Halfon and Kaliaguine, 1976; Beckman and Farmer, 1987; Söhnel et al., 1988; Zumstein and Rousseau, 1989; Söhnel and Mullin, 1992).

\section{Bimodal crystal-size distribution of calcite}

Crystal-size distributions determined by a Microtrac particle analyzer for the $\mathrm{pH}$-stat semibatch seeded runs from run 55 to run 57 at the operating time of $360 \mathrm{~min}$, exhibit bimodal distributions, as shown in Figure 5. The single crystals are well represented by the first population peak within the size range



Figure 3. Population density as a function of crystal size for run S.2.

$P_{1}=17.36 ; P_{2}=-0.01110(1 / \mu \mathrm{m}) ; P_{3}=-0.05551(1 / \mu \mathrm{m})^{0.5}$.

$0-10 \mu \mathrm{m}$, while the existence of agglomerates can be illustrated by the second population peak in the range of $20-100 \mu \mathrm{m}$. Figure 6 revealed that the agglomerates comprise small crystals in these runs. The amount of seed added to runs 55, 56 and 57 were $40 \mathrm{mg}, 60 \mathrm{mg}$, and $80 \mathrm{mg}$, respectively. In these runs, the operating conditions, including $\mathrm{pH}$, operating time, and

Table 3. Parameters in Eq. 17, Effective Nucleation Rates,

\begin{tabular}{|c|c|c|c|c|c|c|}
\hline $\begin{array}{l}\text { Run } \\
\text { No. }\end{array}$ & $P_{1}$ & $\begin{array}{l}P_{2}\left(10^{3}\right) \\
(1 / \mu \mathrm{m}) \\
\end{array}$ & $\begin{array}{c}P_{3}\left(10^{2}\right) \\
(1 / \mu \mathrm{m})^{0.5}\end{array}$ & $\begin{array}{l}n(L)\left(10^{-15}\right) \\
\left(\mathrm{No} . / \mathrm{m}^{3} \cdot \mathrm{m}\right)\end{array}$ & $\begin{array}{c}B\left(10^{6}\right) \\
\left(\mathrm{No} . / \mathrm{m}^{3} \cdot \mathrm{m}\right)\end{array}$ & $\begin{array}{c}N(L)\left(10^{-10}\right) \\
\left(\mathrm{No} . / \mathrm{m}^{3}\right)\end{array}$ \\
\hline S-1 & 18.06 & -7.326 & -7.192 & 5.94 & 3.22 & 2.75 \\
\hline S-2 & 17.36 & -11.10 & -5.551 & 4.21 & 2.73 & 1.66 \\
\hline S-3 & 16.58 & -10.66 & -3.317 & 3.84 & 0.83 & 1.64 \\
\hline S-4 & 15.54 & -13.86 & -0.411 & 2.94 & 2.85 & 1.71 \\
\hline S-5 & 16.48 & -1.707 & -8.517 & 1.39 & 0.52 & 0.74 \\
\hline S-6 & 15.53 & -15.61 & -2.161 & 1.58 & 1.29 & 0.70 \\
\hline S-7 & 17.19 & $-\mathbf{3 . 0 7 9}$ & -7.143 & 3.46 & 1.39 & 1.67 \\
\hline S-8 & 15.42 & -10.91 & -0.941 & 2.37 & 1.26 & 1.54 \\
\hline S-9 & 18.88 & -5.624 & -9.729 & 6.48 & 1.96 & 2.34 \\
\hline S-10 & 18.30 & -6.893 & -7.394 & 7.06 & 3.75 & 2.04 \\
\hline S-11 & 17.89 & -13.33 & -2.789 & 1.27 & 2.36 & 4.67 \\
\hline S-12 & 15.93 & -8.673 & -7.634 & 4.48 & 2.14 & 3.21 \\
\hline S-13 & 16.99 & -9.662 & -3.007 & 6.36 & 5.18 & 3.41 \\
\hline$S-14$ & 18.36 & -8.972 & -3.913 & 5.01 & 5.21 & 7.84 \\
\hline S-15 & 17.71 & -14.37 & -2.136 & 2.59 & 3.83 & 4.58 \\
\hline S-16 & 17.58 & -5.582 & -5.608 & 6.50 & 1.41 & 2.79 \\
\hline
\end{tabular}
and Total Crystal Number at $L=3 \mu \mathrm{m}$ for Seeded Experiments in an MSMPR Crystallizer 


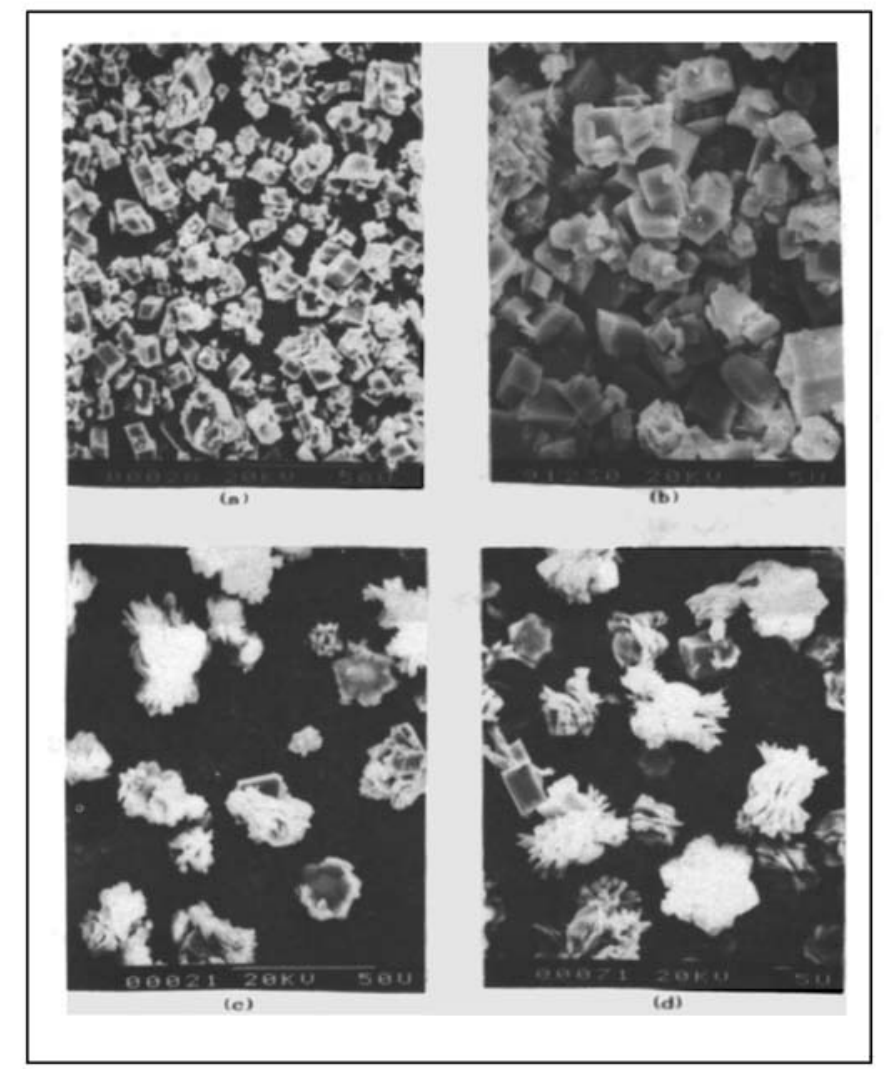

Figure 4. Particle morphology of calcium carbonate.
(a) calcite, run S-2
(b) calcite, run S-8,
(c) solid mixture of aragonite and calcite, run U-19 (d) solid mixture of aragonite and calcite obtained from an un-
seeded pH-stat semibatch crystallizer.

initial solution compositions, are kept the same. The degree of agglomeration seems to increase with increasing seed weight. First, as can be seen in Figure 5a, the crystal-size distribution (CSD) in the first population peak is more significant than the second population peak, while the first population peak is reduced and the CSD shifts to right due to agglomeration as the seed weight increased in Figure 5b. Subsequently, the first population peak disappears and a broader CSD is obtained as shown in Figure $5 \mathrm{c}$ for run 57, attributed to the strong agglomeration when we compare Figure $6 \mathrm{c}$ with $6 \mathrm{a}$ and $6 \mathrm{~b}$. Generally speaking, the higher the nuclei number generated by contact mechanism, the more chances the nuclei to collide with each other within the crystallizer, and thus producing more agglomerates. A similar bimodal CSD was also observed by Wachi and Jones (1991) and Hostomsky and Jones (1991) in the precipitation study of calcium carbonate without seeding. Additionally, a bimodal CSD due to agglomeration was reported for other systems without seeding, such as $\mathrm{SrMoO}_{4}$ by Söhnel et al. (1988) and $\mathrm{BaMoO}_{4}, \mathrm{BaWO}_{4}$ and $\mathrm{SrMoO}_{4}$ by Söhnel and Mullin (1992).

In the MSMPR crystallization study, the bimodal CSD obtained at steady-state operation was also found by the Microtrac particle-analyzer measurement. Typical examples, including runs 2,16 , and 8 , were presented in Figure 7 . The first population peak in Figure $7 \mathrm{a}$ for run 2 was dominant, indicating that a large portion of crystals exists as single crystal,

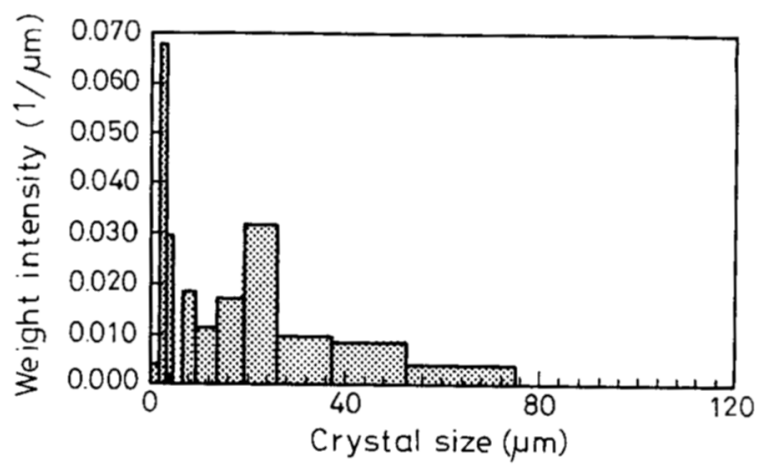

(a)

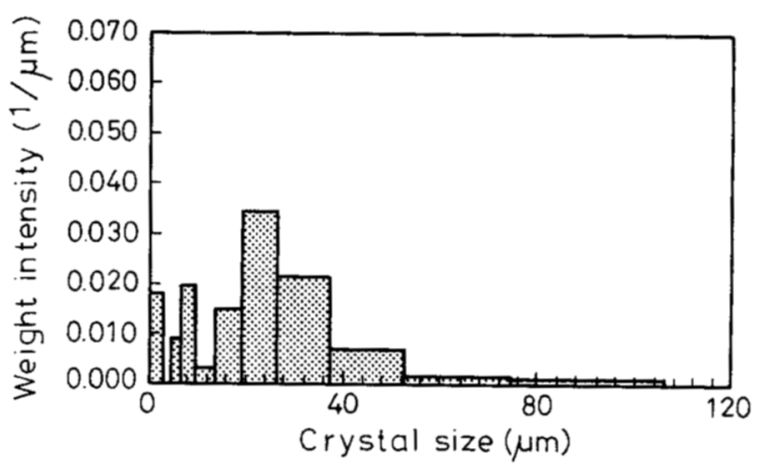

(b)



(c)

Figure 5. Crystal-size distributions in the pH-stat semibatch study at the same operating conditions except the amount of seed.

(a) $m_{o}=40 \mathrm{mg}$, run B-55; (b) $m_{o}=60 \mathrm{mg}$, run B-56; (c) $m_{o}=80$ $\mathrm{mg}$, run $\mathrm{B}-57$

while the first population peak in Figure $7 \mathrm{c}$ for run 8 was diminished and a broader CSD had developed. Evidence of agglomeration is presented in Figure $4 \mathrm{a}$ and $4 \mathrm{~b}$, which are the SEM photographs of the product of runs 2 and 8 , respectively. Ratios of $B_{\text {cor }}^{*} / B^{*}$ was an excellent indicator to illustrate the degree of agglomeration. The corresponding values of $B_{\mathrm{cor}}^{*} /$ $B^{*}$ for runs S-2, S- 16 , and S-8 were $2.08,3.23$, and 4.32 , respectively, denoting that the degree of agglomeration is much higher in run S-8 than in run S-2.

\section{Agglomeration mechanism of calcite}

Figure 8 is a typical example of the development of crystal- 


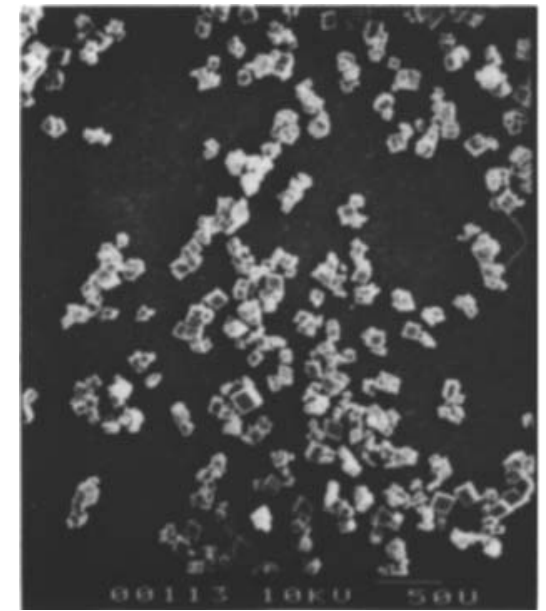

(a)



(b)

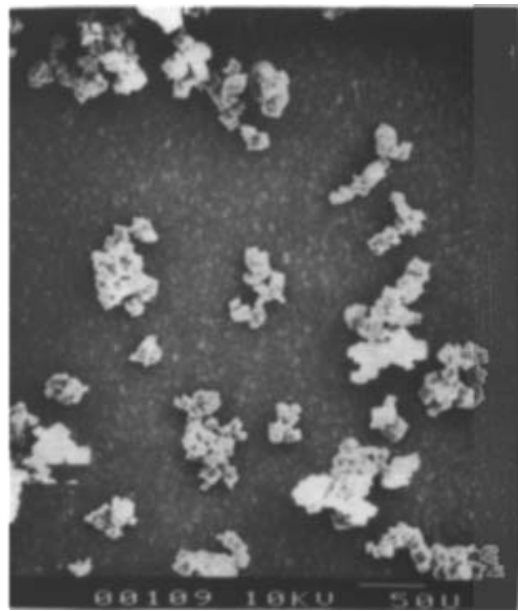

(c)

Figure 6. SEM photographs of calcite obtained from contact mechanism in the $\mathrm{pH}$-stat semibatch study at various amount of seeding.

(a) $m_{o}=40 \mathrm{mg}$, run B-55; (b) $m_{o}=60 \mathrm{mg}$, run B-56; (c) $m_{0}=80 \mathrm{mg}$, run B-57.

size distribution in a seeded experiment. Particle-size distributions were determined by the Galai CIS-1 sizer. Generally speaking, agglomeration of crystals occurring at initial stage was slow because the nuclei number generated by contact mechanism was limited. As can be seen in Figure 8, the number of large particles was much less than the number of small particles at the elapsed times between $30 \mathrm{~min}$ and $150 \mathrm{~min}$. Later on, the bimodal CSD appeared when the elapsed time was greater than $240 \mathrm{~min}$. This could be caused by the agglomeration among the smaller crystals, as reported by Wachi and Jones (1991) for calcite and Hostomsky and Jones (1991) for vaterite. Similar observation of bimodal distribution has been reported for other systems, such as Beckman and Farmer (1987) for barite and Söhnel and Mullin (1992) for $\mathrm{BaMoO}_{4}$. Evidence



(a)



(b)

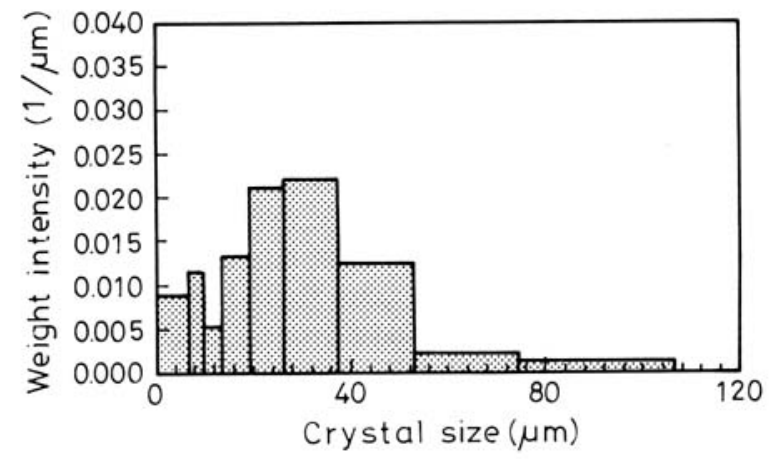

(c)

Figure 7. Bimodal distributions from the MSMPR crystallization study at various $B_{\text {cor }}^{*} / B^{*}$ ratios.

(a) $B_{\mathrm{cor}}^{*} / B^{*}=2.08$, run S-2; (b) $B_{\mathrm{cor}}^{*} / B^{*}=3.23$, run S-16; (c) $B_{\mathrm{cor}}^{*} /$ $B^{*}=4.32$, run $\mathrm{S}-8$. 




Figure 8. Number density of calcite at various operating times, run S-14.

$$
\begin{aligned}
& \text { : } t=1,440 \mathrm{~min} \quad \bullet: t=150 \mathrm{~min} \\
& \Delta: t=1,160 \mathrm{~min} \quad \times: t=70 \mathrm{~min} \\
& \diamond: t=660 \mathrm{~min} \quad+: t=30 \mathrm{~min} \\
& \text { st: } t=240 \mathrm{~min}
\end{aligned}
$$



Figure 9. Polymorphism of calcium carbonate related to supersaturation and $\mathrm{pH}$ values under different nucleation mechanism, at $30^{\circ} \mathrm{C}$.
(1) Primary nucleation to produce vaterite.
(2) Primary nucleation to produce aragonite.
(3) Primary or secondary nucleation to produce calcite.
(4) Secondary nucleation to produce calcite.
$\square$ : Semibatch primary nucleation of aragonite
0 : CMSMPR primary nucleation of aragonite
- : CMSMPR secondary nucleation of calcite
$\diamond:$ CMSMPR primary nucleation of aragonite with seeding
- : Semibatch primary nucleation of calcite
$\odot$ : CMSMPR primary nucleation of calcite
$\checkmark$ : Semibatch secondary nucleation of calcite with seeding

\section{Polymorphism of calcium carbonate}

The morphology of calcium carbonate obtained in this work was determined by the FTIR spectra and the SEM photographs. In the seeded continuous experiment calcite crystals were obtained in the first 16 runs (run S-1 to run S-16), and a solid mixture of aragonite and calcite was found in run S-17 and run S-18. The FTIR spectra showed that the major peak from run S-1 to run S-16 were all at $1,425 \mathrm{~cm}^{-1}$, which was close to the major peak of calcite crystals that was reported in the standard spectra (Vandeberg, 1980). On the other hand, aragonite crystals were observed in unseeded runs (from runs $U$ 19 to U-28) except run U-25, in which the calcite crystals was obtained. From the SEM photographs shown in Figure $4 a-4 b$ and Figure 6, the major form of crystals was rhombohedron. Two crystal forms are observed in Figure 4c-4d: rhombohedron of calcite and rosette of aragonite.

Effect of supersaturation and $\mathrm{pH}$ value on the polymorphism of calcium carbonate is presented in Figure 9. Experimental evidences of this work and the previous one (Tai et al., 1993) suggest that calcite crystal produced by secondary mechanism at $\sigma$ lower than 2.91 for a $\mathrm{pH}$ range from 8.5 to 9.0. Calcite crystals can be produced by the primary nucleation mechanism for $\sigma$ around 2.80; one run from the semibatch experiment 
and one run from the continuous operation (run U-25) have been demonstrated. In the $\mathrm{pH}$ range from 8.75 to 10.0 , aragonite produced by the primary mechanism was found for $\sigma$ from 3.25 to 7.00 . However, the spherical vaterite was not found in this work when $\sigma$ was less than 7.0. Experiments for the $\sigma$ value beyond 7.0 were not conducted due to the experimental difficulty in keeping a high supersaturation.

Studies on the polymorphism of calcium carbonate were reported by other authors. Using an unseeded method, Swinney et al. (1982) found that calcite is formed at low supersaturation, while aragonite is produced at higher supersaturation. The operating $\mathrm{pH}$ range and the corresponding relative supersaturation recalculated by us is also presented in Figure 9. It was found that pure calcite crystals can be prepared from primary mechanism at $\mathrm{pH}=10.6$ and $\sigma$ between 2.53 and 3.34, which includes the supersaturation 2.80 found in this study. On the other hand, pure aragonite crystals were produced in a $\mathrm{pH}$ range between 9.84 and 11.11; the corresponding relative supersaturation range was from 3.20 to 5.86. At higher supersaturation, Kralj et al. (1990) found that the pure vaterite was produced in a pH range from 9.3 to 9.7 at an initial concentration of $2.5 \mathrm{mM}$ for calcium chloride and sodium carbonate, allowing only a slight concentration deviation. The relative supersaturation recalculated here is between 6.5 and 8.5 , as shown in Figure 9. In addition, crystallization study on the calcium carbonate was also investigated without seeding by several authors (Peters and Chang, 1987; Wary and Daniels, 1957; Hostomsky and Jones, 1991). In the investigations, there are no available data to recalculate the relative supersaturation at the given $\mathrm{pH}$ values; therefore, they are not included in Figure 9.

The polymorphism of calcium carbonate was formed at different relative supersaturation levels. At low to moderate relative supersaturation $(\sigma<2.91)$, calcite was formed due to contact mechanism. At higher relative supersaturation $(\sigma>3.25$ in run S-17 and run S-18), the primary nucleation mechanism to produce aragonite was dominating, even in seeded experiments. It is clear that the production of calcite crystal is difficult by the primary mechanism. On the other hand, calcite crystals are produced at lower supersaturation by the seeded technique as demonstrated in this experiment.

\section{Conclusions}

Contact nucleation of calcite has been observed in a continuous MSMPR crystallizer and in a semibatch crystallizer. When the $\mathrm{pH}$ value of the crystallization solution is kept constant and the relative supersaturation is confined under 2.91, calcite crystals of rhombic shape are produced under the wellcontrolled conditions. At higher supersaturation or higher $\mathrm{pH}$ value, rosette agglomerates of aragonite appear. Breakage and agglomeration should be considered in the determination of crystal-size distribution of calcite produced from a continuous MSMPR crystallizer. Breakage of agglomerates is significant at the transient state, while the agglomeration becomes important at the steady-state operation. It seems that strong crystalline bridges formed within the agglomerate of calcite crystals are rigid enough to withstand a continuous high-speed agitation. The agglomeration rate of calcite crystals increases with magma density and relative supersaturation at the steady-state operation. Neglect of agglomeration may result in an under- estimation of nucleation rate; values of one-fifth to one-half of the actual rate are estimated in this experiment.

\section{Acknowledgment}

The authors gratefully acknowledge the financial support of National Science Council of the Republic of China through grant NSC 80-0402-E002-20.

\section{Notation}

$a_{i}=$ activity of solute $i$ in the solution, $\mathrm{kmol} / \mathrm{m}^{3}$

$A=$ agglomeration rate constant, $\mathrm{No} . / \mathrm{m}^{3} \cdot\left(\mathrm{N} / \mathrm{m}^{3}\right)^{2}$

$B=$ nucleation rate at size $L, \mathrm{No} . / \mathrm{m}^{3} \cdot \mathrm{s}$

$B^{*}=$ effective nucleation rate, No. $/ \mathrm{m}^{3} \cdot \mathrm{s}$

$B_{\text {cor }}^{*}=$ corrected nucleation rate, No. $/ \mathrm{m}^{3} \cdot \mathrm{s}$

$\mathrm{C}_{o}=$ concentration of acid or base, $\mathrm{kmol} / \mathrm{m}^{3}$

$C_{1}=$ feed concentrations of $\mathrm{Na}_{2} \mathrm{CO}_{3}$ and $\mathrm{CaCl}_{2}, \mathrm{kmol} / \mathrm{m}^{3}$

$C_{2}=$ concentration of nonreacting components, $\mathrm{kmol} / \mathrm{m}^{3}$

$G=$ linear growth rate, $\mathrm{m} / \mathrm{s}$

IP = ionic product, $\mathrm{kmol} / \mathrm{m}^{32}$

$K_{a}=$ agglomeration rate constant

$K_{b}=$ nucleation rate constant

$K_{\mathrm{sp}}=$ solubility product, $\left(\mathrm{kmol} / \mathrm{m}^{3}\right)^{2}$

$L=$ crystal size, $\mathrm{m}$

$m_{o}=$ seed weight in the crystallizer, $\mathrm{mg}$

$M_{t}=$ magma density, $\mathrm{kg} / \mathrm{m}^{3}$

$n=$ population density, No. $/ \mathrm{m}^{3} \cdot \mathrm{m}$

$n_{i}=$ average particle number per unit volume at size $i$, No. $/ \mathrm{m}^{3}$

$N=$ total number of crystals, No. $/ \mathrm{m}^{3}$

$P_{i}=$ parameters in Eq. 17, $i=1-3$

$Q_{o}=$ volumetric flow rate of acid or base, $\mathrm{m}^{3} / \mathrm{s}$

$Q_{1}=$ volumetric flow rate of feed stream, $\mathrm{m}^{3} / \mathrm{s}$

$r_{a}=$ agglomeration rate defined in Eq. $3, \mathrm{No} . / \mathrm{m}^{3} \cdot \mathrm{m} \cdot \mathrm{s}$

$R a=$ agglomeration rate defined in Eq. 7, No. $/ \mathrm{m}^{3} \cdot \mathrm{s}$

$t=$ time, $\mathrm{s}$

$\mathrm{TCA}=$ total calcium concentration, $\mathrm{kmol} / \mathrm{m}^{3}$

$\mathrm{TCl}=$ total chloride concentration, $\mathrm{kmol} / \mathrm{m}^{3}$

$\mathrm{TCO}=$ total carbonate concentration, $\mathrm{kmol} / \mathrm{m}^{3}$

TNA $=$ total sodium concentration, $\mathrm{kmol} / \mathrm{m}^{3}$

\section{Greek letters}

$\beta=$ agglomeration kernel

$\tau=$ mean residence time

\section{Literature Cited}

Bhatia, S. K., and D. Chakraborty, "Modified MWR Approach: Application to Agglomerative Precipitation," AIChE J., 38(6), 868 (1992).

Beckman, J. R., and R. W. Farmer, "Biomodal CSD Barite Due to Agglomeration in an MSMPR Crystallizer," AIChE Symp. Ser., 83(253), 85 (1987).

Budz, J., A. G. Jones, and J. W. Mullin, "Agglomeration of Potassium Sulfate Crystals in an MSMPR Crystallizer," AIChE Symp. Ser., 83(253), 79 (1987).

Chen, Pao-Chi, "The Precipitation and Crystallization of Sparingly Soluble Salts," PhD Diss., National Taiwan Univ., Taipei (1992).

Chen, P. C., C. Y. Tai, and S. M. Shih, "Control of Crystal Habit and Particle Morphology of Calcium Sulfite Hemihydrate Crystals," J. Crystal Growth, 123, 277 (1992).

Christoffersen, J., and M. R. Christoffersen, "Kinetics of Spiral Growth of Calcite Crystals and Determination of Absolute Rate Constant," J. Crystal Growth, 100, 203 (1990).

Dirksen, J. A., S. Benjelloun, and T. A. Ring, "Modelling the Precipitation of Copper Oxilate Aggregates," Coll. Polym. Sci., 268, 864 (1990).

Etherton, D. L., and A. D. Randolph, "Nucleation/Growth Rate Kinetics of Gypsum in Simulated FGD Liquids: Some Process Configurations for Increasing Particle Size,' AIChE Symp. Ser. , 77(211), 87 (1981). 
Garside, J., "Tailoring Crystal Products in Precipitation Processes and The Role of Mixing," AlChE Symp. Ser., 87(284), 16 (1992).

Giannimaras, E. K., and P. G. Koutsoukos, "The Crystallization of Calcite in the Presence of Othophosphate," J. Coll. Interf. Sci., 116(2), 423 (1987).

Halfon, A., and S. Kaliaguine, "Alumina Trihydrate CrystallizationPart 2. A Model of Agglomeration," Can. J. Chem. Eng., 54(6), 168 (1976).

Henisch, H. K., Crystal Growth in Gels, 1st ed., Pennsylvania State University Press, University Park and London (1973).

Hostomsky, J., and A. G. Jones, "Calcium Carbonate Crystallization, Agglomeration and Form During Continuous Precipitation from Solution," J. Phys. D:Appl. Phys., 24, 165 (1991).

Hounslow, M. J., "A Discretized Population Balance for Continuous Systems at Steady State," AIChE J., 36(1), 106 (1990).

Hulburt, H. M., and S. Katz, "Some Problems in Particle Technology," Chem. Eng. Sci., 19, 555 (1964).

Jones, A. G., J. Budz, and J. W. Mullin, "Crystallization Kinetics of Potassium Sulfate in a CMSMPR Agitated Vessel," AIChE J., 32, 2002 (1986).

Kazmlerczak, T. F., M. B. Tomson, and G. H. Nancollas, "Crystal Growth of Calcium Carbonate. A Controlled Composition Kinetic Study," J. Phys. Chem., 86, 103 (1982).

Kralj, D., L. Brecevic, and A. E. Nielsen, "Vaterite Growth and Dissolution in Aqueous Solution. I. Kinetics of Crystal Growth," J. Crystal Growth, 104, 793 (1990).

Liao, P. F., and H. W. Hulburt, "Agglomeration Process in Suspension Crystallization," AIChE Meeting, Chicago (Dec., 1976).

Marchal, P., R. David, J. P. Klein, and J. Villermaux, "Crystallization and Precipitation Engineering-I. An Efficient Method for Solving Population Balance in Crystallization with Agglomeration," Chem. Eng. Sci., 43(1), 59 (1988).

Mullin, J. W., Crystallization, Butterworth, London (1972).

Nancollas, G. H., Interactions in Electrolyte Solution, Elsevier, Amsterdam (1966).

Nielsen, A. E., and J. M. Toft, "Electrolyte Crystal Growth Kinetics," J. Crystal Growth, 67, 278 (1984)

Peters, R. W., and T. K. Chang, "The Effect of $\mathrm{Pb}(\mathrm{II})$ as a Trace Impurity on the Crystallization Kinetics of $\mathrm{CaCO}_{3}$ Precipitation," AIChE Symp. Ser., 83(253), 62 (1987).

Randolph, A. D., and M. A. Larson, Theory of Particulate Processes, 2nd ed., Chap. 4, Academic Press, New York (1988).
Ring, T. A., "Nucleation, Growth and Agglomeration during Precipitation of Powders," Proc. 2nd World Cong. Part. Technol,, Kyoto, Japan, p. 497 (Sept. 19-22, 1990).

Sastry, Kalanadh V. S., and D. H. Fuerstenau, "Size Distribution of Agglomerates in Coalescing Dispersed Phase Systems," Int. Eng. Chem. Foundam., 9, 145 (1970).

Schierhoize, P. M., and J. D. Stevens, "Determination of the Kinetics of Precipitation in a Dilute System," AIChE Symp. Ser. (Water), 71(151), 248 (1975).

Söhnel, O., and J. W. Mullin, "Precipitation of Calcium Carbonate," J. Crystal Growth, 60, 239 (1982).

Söhnel, O., J. W. Mullin, and A. G. Jones, "Crystallization and Agglomeration Kinetics in the Batch Precipitation of Strontium Molybdate," Ind. Eng. Chem. Res., 27, 1721 (1988).

Söhnel, O., and J. W. Mullin, "Agglomeration in Batch Precipitated Suspensions," AIChE Symp. Ser., 87(284), 182 (1992).

Swinney, L. D., J. D. Stevens, and R. W. Peter, "Calcium Carbonate Crystallization Kinetics," Ind. Eng. Chem. Foundam., 21, 31 (1982).

Tai, C. Y., P. C. Chen, and S. M. Shih, "Size-Dependent Growth and Contact Nucleation of Calcite Crystals," AIChE J., 39, 1472 (1993).

Tavare, N. S., M. B. Shah, and J. Garside, "Crystallization and Agglomeration Kinetics of Nickel Ammonium Sulphate in an MSMPR Crystallizer," Powder Technol, 44, 13 (1985).

Tavare, N. S., and A. V. Patwardhan, "Agglomeration in a Continuous MSMPR Crystallizer,"' AIChE J., 38(3), 377 (1992).

Tsuge, H., Y. Kotaki, and S. I. Hibino, "Reactive Crystallization of Calcium Carbonate by Liquid-Liquid Reaction," $J$. Chem. Eng. Jpn., 20(4), 374 (1987).

Wachi, S., and A. G. Jones, "Effect of Gas-Liquid Mass Transfer on Crystal Size Distribution During the Batch Precipitation of Calcium Carbonate," Chem. Eng. Sci., 46(12), 3289 (1991).

Wary, J., and F. Daniels, "Precipitation of Calcite and Aragonite," J. Am. Chem. Soc., 79, 2031 (1957).

Zumstein, R. C., and R. W. Rousseau, "Agglomeration of Copper Sulfate Pentahydrate Crystals Within Well-Mixed Crystallizers," Chem. Eng. Sci., 44(10), 2149 (1989).

Manuscript received Oct. 4, 1994, and revision received Jan. 13, 1994. 